\title{
RESENHA DE MACHADO DE ASSIS, UMA APRESENTAÇÃO, DE JOÃO HERNESTO WEBER
}

\section{REVIEW OF MACHADO DE ASSIS, UMA APRESENTAÇÃO, BY JOÃO HERNESTO WEBER}

WEBER, João Hernesto. Machado de Assis, uma apresentação. Porto Alegre: Movimento, 2013. 158 p.

\section{Eugênio Vinci de Moraes \\ Centro Universitário Uninter \\ Curitiba, Paraná, Brasil}

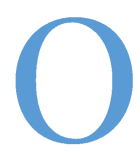

riginalmente escrito como introdução ao projeto de digitalização das obras completas de Machado de Assis para internet, realizada pelo Núcleo de Pesquisa em Informação, Literatura e Linguística da UFSC, de 2008, Machado de Assis, uma apresentação (Porto Alegre: Movimento, 2013), de João Hernesto Weber, professor aposentado da Universidade de Santa Catarina (UFSC), dá a conhecer de forma elegante e percuciente a obra de Machado. Segundo o autor, este livro é "uma espécie de introdução à leitura da obra Machado de Assis", balizada pela perspectiva materialista, tributária da crítica de esquerda, em especial a de Antonio Candido e Roberto Schwarz.

Organizado em sete capítulos, Weber lança um arco sobre toda a obra de Machado analisando os gêneros em que o escritor fluminense escreveu, incluindo a crítica. Apesar da ênfase ao romance, cujas páginas ocupam quase metade do livro, os ensaios dedicados ao exercício da crítica e ao conto são importantes para a compreensão geral da obra machadiana. Na verdade, sem deixar de apresentar a literatura de Machado ao leitor iniciante, o livro propõe leituras bastante especiais, que aliam, como no caso dos romances e contos, didática e argúcia interpretativa. Os capítulos dedicados ao teatro, à crônica e à poesia, embora breves, amarram-se aos temas e formas tratados nos demais capítulos.

Antes de abordar a obra do escritor, Weber passeia rapidamente, no primeiro capítulo, pela fortuna crítica machadiana, sobretudo para demarcar 
a perspectiva que adota para ler Machado. Ele a chama de "leitura históricoestrutural da obra de Machado". ${ }^{1}$ Por meio dessa perspectiva, ele percorre a obra machadiana sob três aspectos. No primeiro, ele relaciona a visada crítica do escritor à construção da sua poética. No outro, envereda pela questão do estilo, ou seja, pela dicção que pôde dar "forma à formação social do Brasil" ${ }^{2}$ do Oitocentos. O terceiro aspecto se detém nas formas pelas quais o mundo "externo" vira - mediante abstração - forma "interna"3.

Weber passa então a analisar, no capítulo seguinte, os três dos mais importantes ensaios críticos de Machado: "Instinto de Nacionalidade" (1873), "O Primo Basílio" (1878) e "A nova geração" (1879). Para ele, o papel da crítica machadiana vai além da interpretação ou análise de obras literárias, pois ela lhe serviu como atividade de construção de sua poética. Ao ler autores locais e estrangeiros o escritor soube divisar os vazios não preenchidos pela literatura brasileira que sua obra de ficção poderia ocupar. Machado, segundo Weber, propôs-se a "rastrear e estudar a tradição e de se preparar para nela intervir."4

Weber mostra-nos esse escritor "rastreador", primeiro apresentando-o firmando seu ponto de vista através das reflexões de "Instinto de nacionalidade". Machado descontrói e reconstrói a tradição fazendo ver que o Romantismo e seus temas não devem nem ser exclusivos nem excluídos de nossa literatura: tudo deve ser submetido a um sentimento íntimo, que Weber traduz como "o lugar onde se observa o mundo". ${ }^{5}$ Machado vai circunscrevendo o cenário no qual a literatura brasileira insere-se. Falta-lhe intervir nesse cenário.

Isso demandará ainda um exame dos gêneros literários, segundo modo pelo qual Machado, de acordo com Weber, exerce sua crítica nos outros dois ensaios, "O Primo Basílio" e "A nova geração". Neles, o escritor fluminense percebe o "brete" em que se encontrava", ${ }^{6}$ espremido entre o Romantismo que reinava no Brasil e o real-naturalismo que se fortalecia na Europa e desembarcava com força no país. Weber mostra como Machado recusa o viés

\footnotetext{
${ }^{1}$ WEBER, Machado de Assis, uma apresentação, p. 18.

${ }^{2}$ Ibidem.

${ }^{3}$ Ibidem.

${ }^{4}$ Idem, p. 29.

5 Idem, p. 26.

${ }^{6}$ Idem, p. 31.
} 
descritivista do Real-Naturalismo e defende a narrativa do drama moral das personagens.

Nem Romantismo nem Realismo-Naturalismo, resta a "terceira margem".

Nesta outra margem, o escritor busca um "espaço de libertação", 8 que Weber vai indicar através da polêmica gerada pela crítica a Sílvio Romero feita por Machado em uma página do "A nova geração". Ao dizer que o crítico sergipano apenas "balbucia a língua nacional", 9 Machado recebe de volta nas páginas da História da literatura brasileira de Romero o petardo que ficará famoso: "Machado repisa [...] tanto suas ideias [...] que deixam-nos a impressão dum tal ou tal tartamudear". ${ }^{10}$ Mas vendo a resposta de Romero pelo avesso, pode-se compreender o estilo de Machado, segundo Weber: "O estilo 'tartamudo', retorcido de Machado de Assis pode ser visto como o caminho para ele poder ter dito tudo o que disse em pleno II Império". ${ }^{11}$ Esse estilo insólito seria a margem possível para o escritor de seu tempo e de seu país dar conta de "formalizar literariamente a forma social". ${ }^{12}$

Assim chega-se ao capítulo dedicado ao romance machadiano. Além de se posicionar em relação à já clássica discussão da aclimatação do romance burguês europeu em nação periférica - partindo os romances de Machado pela ótica schwarziana do "olhar de baixo" e o "olhar de cima"13 -, Weber propõe uma organização das posições morais das personagens da primeira fase e do modo de narrar das ficções da segunda.

Weber vê a trajetória do Machado romancista não pela perspectiva do acúmulo de experiências, mas sim pelo vai e vem das experimentações. Em cada fase, Machado estaria ensaiando uma forma, que, mesmo dominante, se sujeitaria a experimentações. Assim, a aclimatação do romance europeu para as condições locais se daria à base de experiências formais e não por imitação pura e simples de modelos literários do Oitocentos.

Nos romances da primeira fase, Machado busca narrar a situação da mulher livre mas pobre submetida ao regime do favor. Usando quadros

\footnotetext{
${ }^{7}$ Idem, p. 35.

${ }^{8}$ Idem, p. 34.

${ }^{9}$ ASSIS, A nova geração, p. 828.

${ }^{10}$ Apud WEBER, cit. p.37.

${ }^{11}$ WEBER, cit., p. 38.

${ }^{12}$ Idem, p. 35.

${ }^{13}$ Idem, p. 46.
} 
mediante os quais compara os perfis das personagens centrais dos romances, Weber as classifica de acordo com o êxito e fracasso delas em relação à ascensão social: Guiomar de A mão e a luva, e Iaiá de Iaiá Garcia são o par bem sucedido, ao passo que Helena, do romance de mesmo nome, e Estela, de Iaiá Garcia, teriam renunciado - ainda que de modos diferentes - à subida social. Haveria aí, segundo Weber, estudos retilíneos dos dramas morais, pares antitéticos, mas não dialéticos, como ocorrerá com Capitu: "Machado [...] não dialetiza, enfim, suas personagens como o faria com Capitu, por exemplo, em que juntaria [...] as personagens femininas numa única e complexa figura $[. . .]^{\prime \prime}{ }^{14}$ De fundo, ainda haveria uma visão moralizante conservadora que abafaria a situação assimétrica posta nesses romances.

Tudo isso se reverteria nos romances da segunda fase. Weber enfatiza o salto, a virada de perspectiva. Além disso, as experiências de Machado deixam de acontecer separadamente e estanques em cada romance para ser o motor de seu estilo, "adotando o ir e vir da narrativa livre". ${ }^{15}$ Tudo passa ser jogo - regrado pela "sordidez da classe dominante"16 - que demanda um leitor atento, dado que há duas instâncias a serem vistas, segundo Weber: o estilo ébrio, sinal da errância da narrativa e do próprio Brasil do século XIX; e os contínuos velamentos e insinuações que suscitam tanto uma decifração superficial quanto uma lata e mais profunda, digamos alegórica - para lembrar John Gledson, ${ }^{17}$ outra fonte de Weber -, do Brasil do Segundo Reinado. Weber exercitará esse modo de ler a obra machadiana, por exemplo, mediante o desnudamento do episódio de Eugênia, a coxa, de Memórias póstumas de Brás Cubas.

Depois de analisar os demais romances da segunda fase, Weber se detém em Casa velha, que considera uma experiência que se fixa na fronteira entre as primeira e segunda fases do romance machadiano. Primeiro, Weber compara Casa Velha ao esquema de ascensão social dos romances anteriores a Memórias póstumas. Lalau, a personagem central, renuncia ao amor pelo senhor, Félix, filho de dona Antonia, e casa-se com alguém de sua classe, encaixando-se no perfil da renúncia, esboçado antes por Weber. Mas publicada em meados dos anos 1880, essa novela situa-se temporalmente na chamada segunda fase e faz uso do narrador em primeira pessoa. Esse

\footnotetext{
${ }^{14}$ Idem, p. 65.

${ }^{15}$ Idem, p. 70.

${ }^{16}$ Idem, p. 69.

${ }^{17}$ Ver GLEDSON, Machado de Assis: ficção e história.
} 
narrador, um padre, mete-se na história, inserindo seus interesses, que têm as tinturas da visão da classe dominante, da "ótica de cima". Weber descreve esses dois aspectos carimbando seus intérpretes: Lúcia Miguel Pereira e John Gledson, cujas interpretações Weber procura fundir:

\begin{abstract}
Nesse sentido não é o caso de contrapor os dois, mas de perceber a dupla dimensão de Casa Velha, romance atrelado, de um lado, ao esquema narrativo vigente na "primeira fase" e, de outro, abrindo caminho, através do padre narrador, aos grandes romances da segunda fase, quando Machado desloca o ponto de vista do narrador-mediador para o narrador-senhor de escravos, Brás Cubas e Bento Santiago. ${ }^{18}$
\end{abstract}

Fundamental também para seu ponto de vista acerca de Machado é a análise que faz dos seus contos. De forma até surpreendente dado o espaço que reserva a eles, Weber diz que "nos contos [...] encontra-se a essência de Machado".$^{19}$ Nos contos, a terceira margem estaria no rebaixamento do conto fantástico à condição local, por meio da reposição do duplo no campo da sociedade escravista, que oscilava entre o passado colonial e a modernidade. Para Weber, os temas machadianos como a loucura, a errância, o nonsense marcam a impossibilidade do indivíduo realizar-se totalmente, indo e vindo entre o "não ser e o ser outro", como na célebre formulação de Paulo Emílio Salles Gomes. ${ }^{20}$

Assim, Machado de Assis, uma apresentação, além de alcançar plenamente seu fim - dar a conhecer de maneira organizada e didática a obra machadiana - insere interpretações percucientes e inquietantes sobre esse escritor, que já o incorpora - ainda que modestamente, como quer o autor - à fortuna crítica machadiana. Talvez algum leitor sinta falta da discussão daqueles textos híbridos com os quais Machado experimentou novos estilos de narrar, como "Antes da missa", "Um cão de lata ao rabo", "Elogio da vaidade" que fazem par com outros textos da década de 1870. São pontas muito visíveis das formas experimentais que Machado buscou em toda sua vida literária, que, assim como Casa velha, muito podem dizer da poética

\footnotetext{
18 WEBER, cit., p. 100.

${ }^{19}$ Idem, p. 123.

${ }^{20}$ SALLES GOMES, Cinema: trajetória no subdesenvolvimento, p. 90.
} 
machadiana. De todo modo, isso não desdiz o livro, já que, sua finalidade, apresentar a obra machadiana, impõe limites, cortes e seleções inevitáveis.

\section{Referências}

ASSIS, Machado de. A nova geração. In: Obra completa, vol. 3. Rio de Janeiro: Nova Aguilar, 1986.

GLEDSON, John. Machado de Assis: ficção e história. São Paulo: Paz e Terra, 1986.

SALLES GOMES, Paulo Emílio. Cinema: trajetória no subdesenvolvimento. São Paulo: Paz e Terra, 2001.

WEBER, João Hernesto. Machado de Assis, uma apresentação. Porto Alegre: Movimento, 2013.

EUGÊNIO VINCI DE MORAES é bacharel em Língua e Literatura Portuguesa e Italiana (2001) e doutor em Letras (Literatura Brasileira) pela Universidade de São Paulo (2007). É professor do Centro Universitário Uninter (Uninter-PR) desde 2008 e editor da Revista Uninter de Comunicação desde 2013. Traduziu, entre outros, As novelas de Pescara, de Gabrielle D'Annunzio, "O pó da borboleta", de Antonio Tabucchi; e publicou artigos como "O Dante do Cosme Velho" (Revista de História da Biblioteca Nacional). E-mail: <euvinci@gmail.com>

Recebido: 15.09 .14 Aprovado: 29.10 .14 